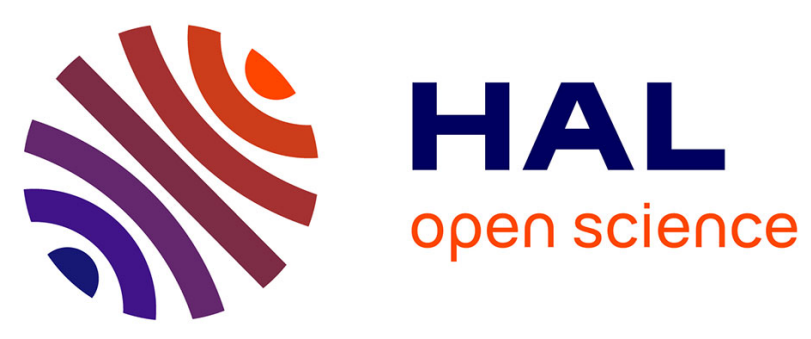

\title{
The decline of Latin VOAux
}

Lieven Danckaert

\section{To cite this version:}

Lieven Danckaert. The decline of Latin VOAux: Neg-incorporation and syntactic reanalysis. Ana Maria Martins; Adriana Cardoso. Word order change, Oxford University Press, pp.243-263, 2018, Oxford Studies in Diachronic and Historical Linguistics, 9780198747307. 10.1093/oso/9780198747307.003.0013 . hal-01968610

\section{HAL Id: hal-01968610 https://hal.science/hal-01968610}

Submitted on 2 Jan 2019

HAL is a multi-disciplinary open access archive for the deposit and dissemination of scientific research documents, whether they are published or not. The documents may come from teaching and research institutions in France or abroad, or from public or private research centers.
L'archive ouverte pluridisciplinaire HAL, est destinée au dépôt et à la diffusion de documents scientifiques de niveau recherche, publiés ou non, émanant des établissements d'enseignement et de recherche français ou étrangers, des laboratoires publics ou privés. 
The decline of Latin VOAux: Neg-incorporation and syntactic reanalysis

\section{Lieven Danckaert (Ghent University, FWO) ${ }^{1}$}

\section{Introduction}

One of the main changes that took place during the evolution from Latin towards the Romance languages is a gradual reduction of word order flexibility. This paper aims at analysing one particular case study of a word order pattern which is available in Classical ${ }^{2}$ but not in Late Latin, viz. the co-occurrence of a head-initial VP and a head-final TP, which yields the order 'VOAux'. I will start the discussion with some general remarks on Latin word order.

1.1 Two directionality alternations in the Latin clause

Throughout the history of Latin, VPs can either be head-final (1a) or head-initial (1b), giving rise to the well known (but ill-understood) OV-VO alternation.

\footnotetext{
${ }^{1}$ The research reported on in this paper was funded by postdoctoral grants of the 'Bijzonder Onderzoeksfonds' (BOF) of Ghent University (grant No. BOF11/PDO/042) and of the 'Fonds voor Wetenschappelijk Onderzoek' (FWO) (grant No. FWO13/PDO/024).

${ }^{2}$ The term 'classical' refers to the period of ca. $100 \mathrm{BC}$ to $200 \mathrm{AD}$, and it is not meant to have any 'stylistic' ('high register') connotations (on the periodization assumed, see section 3.1).
} 
(1) a Caesar exercitu-m redux-it.

(S)OV

Caesar.NOM army-ACC lead.back-PF.3SG

'Caesar led back his army.' (= Caes. Gal. 3.29)

b Pater accep-it benefici-um.

$(\mathrm{S}) \mathrm{VO}$

father.NOM receive-PF.3SG benefit-ACC

'The father received the benefit.' (= Sen. Ben. 5.19.8)

Similarly, TPs show the same mixed behaviour, witness the fact that auxiliaries and dependent non-finite verbs can be linearized in either order. This second alternation is illustrated in (2), showing examples with the modal auxiliary possum 'be able' and an infinitival complement. The same alternation can be observed in clauses with a BE-auxiliary and a past participle (not illustrated).

(2) a grau-ior

poen-a accid-ere pot-u-it.

VPAux heavy-COMP.NOM punishment-NOM happen-PR.INF be.able-PF-3SG

'A heavier punishment could have been pronounced.' (= Cic. prou. cons. 14)

b nihil

opportun-ius

pot-u-it

accid-ere.

AuxVP

nothing.NOM

convenient-COMP.NOM

be.able-PF-3SG happen-PR.INF

'Nothing more convenient could have happened.' (= Cic. Fam. 1.9.9) 
As is well known, in the present day Romance languages VPs and TPs can no longer be headfinal. The origins of the shift towards a rigidly head-initial grammar can be traced back to (Late) Latin: corpus evidence shows that the frequency of the order VPAux decreases over time (at least in clauses with a modal verb and an infinitive, see below). On the other hand, the overall incidence of the order OV remains by and large constant throughout the lifespan of the Latin language (say $200 \mathrm{BC}-600 \mathrm{AD}$ ). More details on the diachrony of these phenomena are provided in section 3 .

Interestingly, in Classical Latin the two directionality alternations (OV-VO and VPAuxAuxVP) seem to be largely independent of one another: in clauses where both can be observed (i.e. in clauses in which (i) an auxiliary, (ii) a transitive non-finite verb and (iii) an overt internal argument co-occur), the headedness of one projection does not determine the headedness of the other. This we can deduce from the fact that the six logically possible orders in which the elements $\mathrm{O}, \mathrm{V}$ and Aux can occur are all attested (albeit at strongly different frequencies, see again section 3 (Tables x.2 and x.3) below).

\subsection{A constraint on word order variation: the 'Final-Over-Final Constraint'}

In the light of recent work on word order variation in the languages on the world (see especially Holmberg 2000; Biberauer, Holmberg and Roberts 2014 (henceforth BHR)), the availability of one of these orders, viz. VOAux, is at first sight surprising. This pattern features a head-initial VP and a head-final TP:

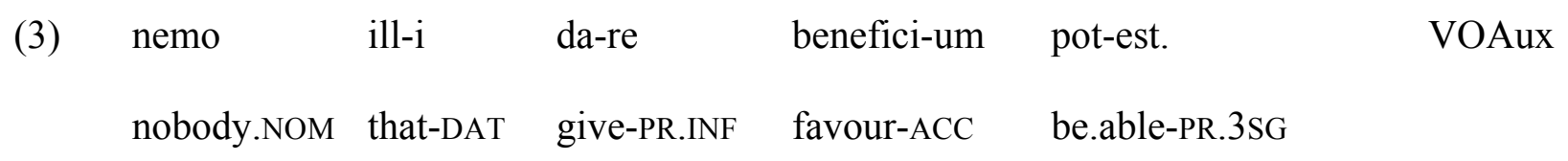


'Nobody can do him a favour.' (= Sen. Ben. 5.12.5)

BHR observe that cross-linguistically, head-final projections tend to dominate only other headfinal projections. A formalization of this descriptive generalization has become known as the 'Final-Over-Final Constraint', henceforth FOFC. As a first approximation, consider an early formulation of this constraint, from Holmberg (2000: 124; (4a) is his (1)). The relevant ungrammatical pattern can be schematically represented as in (4b), where $\alpha \mathrm{P}$ is the complement of $\beta$ and $\gamma \mathrm{P}$ the complement of $\alpha$ :

(4) a If a phrase $\alpha$ is head-initial, then the phrase $\beta$ immediately dominating $\alpha$ is head initial. If $\alpha$ is head-final, $\beta$ can be head-final or head-initial.

$\mathrm{b} *[\beta \mathrm{PP}[\alpha \mathrm{P} \alpha \mathrm{P}] \beta]$

Empirical support in favour of FOFC seems very strong, although occasional counterexamples have been brought up. This paper focuses on one apparent violation of FOFC, namely the Latin VOAux pattern exemplified in (3). In section 2, I discuss the syntax of Classical Latin VOAux, and I suggest that this pattern does not qualify as a genuine counterexample to FOFC. Next, I turn to the diachronic evolution of VOAux (section 3): on the basis of a large-scale corpus study, I show that a strong (but not quite total) decline of the VOAux pattern can be observed. Finally, in section 4 I propose an analysis of this reduction of word order flexibility in terms of a process of syntactic reanalysis, which itself is the result of an independent change in the grammar, namely the incorporation of the preverbal negator non 'not' into the hierarchically highest verb of the clause. 
1.3 A note on the empirical scope of the study

In principle, one can study the syntax and diachrony of the Latin VOAux pattern (i) in clauses with a BE-auxiliary and a participial complement and/or (ii) in clauses with a modal auxiliary complemented by an infinitive. Syntactically, the main difference between these two environments is that only the former straightforwardly qualifies as a monoclausal structure. In the case of the latter, this is less clear (see among many others Roberts (1985) and Cinque (2004) for discussion). As biclausal structures are arguably syntactically more complex than monoclausal ones, it would be optimal to restrict the scope of this study to clauses with a BE-auxiliary, as for instance 0 , in which the VOAux pattern appears in a clause with an analytic form (in boldface) of a transitive deponent verb: $:^{3}$

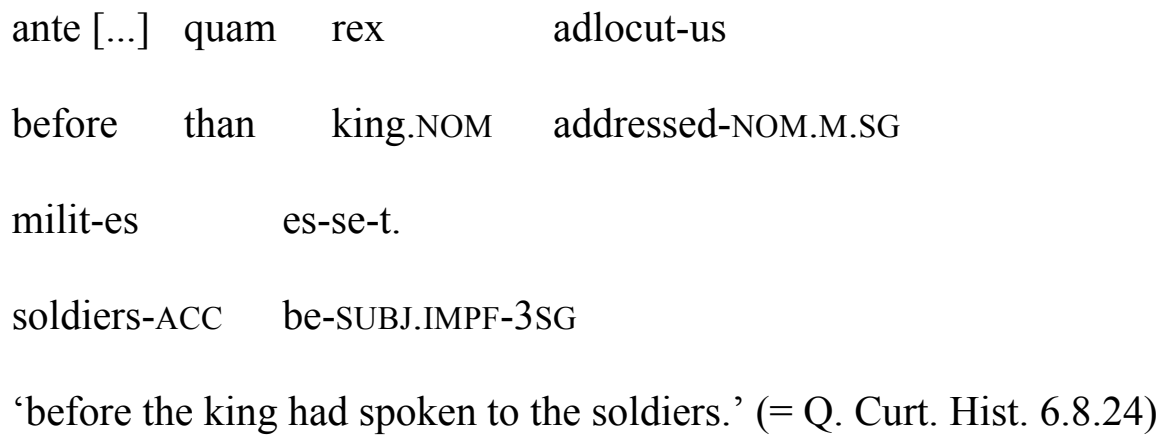

\footnotetext{
${ }^{3}$ More specifically, if structures with a modal auxiliary are indeed biclausal, it would be conceivable that they consist of two separate extended projections. As can be understood from the definition in (9), FOFC only restricts word order in extended projections of a single lexical head. See also footnote 4.
} 
However, clauses with a deponent verb are both harder to retrieve in a corpus and they have a lower token frequency than modals. ${ }^{4}$ Especially the last factor makes it hard to use these structures in a diachronic study. For this reason, only clauses with a modal auxiliary (possum 'be able' or debeo 'have to') were considered in the present paper.

There are reasons to assume that this does not affect the argument. Consider for instance the situation in Early English, in which the order VOAux is never attested, despite both the orders VO and VPAux being productive (Taylor and Pintzuk 2011). Crucially, the ban on VOAux holds across all clauses, irrespective of the type of auxiliary (HAVE or modal) involved (Susan Pintzuk, p.c.). ${ }^{5}$ Therefore, I take it that it is justified to study the Latin VOAux-pattern in the context of modals and their infinitival complements.

2. Classical Latin clause structure and the availability of VOAux

This section starts with a discussion of the synchronic syntax of the two head-final sequences 'OV' and 'VPAux' which are characteristic of Classical Latin. In a nutshell, I will argue that the

\footnotetext{
${ }^{4}$ See Danckaert (in progress) for more detailed discussion. In a corpus of 1965 clauses containing an $\mathrm{O}$, a deponent past participle (V) and a BE-auxiliary, with 1663 clauses from the classical period (ca. $85 \mathrm{BC}-180 \mathrm{AD}$ ), and 302 from Late Latin (after $350 \mathrm{AD}$ ), the VOAux-order is attested 45 times in the earlier period, and never in the later. On the periodization, see section 3.1 below.

${ }^{5}$ Note that it is generally assumed that early English modal verbs were lexical verbs heading their own VP (Roberts 1985), rather than functional verbs base-generated in the same projection line as their infinitival complement, i.e. in an unambiguously monoclausal structure (Cinque 2004).
} 
two are not derived by means of the same mechanism: more specifically, I will suggest that the former involves a very local type of phrasal movement, which gives rise to a configuration where the direct object is still dominated by the top node of the projection headed by the lexical verb (see also Ledgeway 2012). In contrast, the order VPAux will be argued to be derived by means of non-local movement of the verb phrase to a position c-commanding the entire TP. In what follows, I will discuss the details of both of these derivations.

\subsection{OV: strictly local 'roll-up movement'}

Following Kayne (1994), I assume that in contrast with head-complement sequences, complement-head orders are always movement derived. Crucially, there is more than one way in which a complement can be displaced across the head that selects it. In addition to the common distinction between $\mathrm{A}$ and $\mathrm{A}^{\prime}$-movement (to which one might have to add scrambling), work in the antisymmetric tradition has identified another type of phrasal movement, which displaces a complement XP in a very local fashion. When applied repeatedly, this operation gives rise to a 'snowballing' effect (Aboh 2004, Cinque 2005). In what follows, I will try to determine which type of movement each of the two Classical Latin complement-head orders are derived by.

As mentioned, Latin direct objects can appear either to the left or to the right of their selecting predicates. The details of the resulting OV/VO alternation can most clearly be observed in clauses with a non-finite $\mathrm{V}$ and an auxiliary. I will assume that in these contexts, the lexical verb remains within the VP (in situ, or in a low functional projection below T): as a result, V can 
serve as a reference point with respect to which VP-internal object positions can be evaluated. ${ }^{7}$ Consider for instance the examples in (6), which feature two VPAux-clauses. As indicated, I assume that these are derived by means of VP displacement to a position above the functional head occupied by the modal, which I will call T here (with obvious simplifications). The formal properties of this operation will be elaborated on shortly; for present purposes, it is only important to note that two VP-internal object positions need to be distinguished, one of which I take to reflect the base order of the object (6a), and a second one that I is derived through movement $(6 b):^{8}$

(6) a cum

$$
\text { testament-o }
$$

[script-us

here-s

SVOAux because testament-ABL

written-NOM

heir-NOM

euinc-ere hereditat-em]

pos-si-t

$\mathrm{t}_{\mathrm{i}}$ recover-PR.INF heritage-ACC be.able-PR.SUBJ-3SG 'since the heir appointed in the testament can recover the heritage' (= Gai. Inst. 3.36)

b $[\ldots]$ quin $[$ seru-us

$$
\text { benefici-um } \left._{j} \text { da-re } t_{j}\right]_{i} \quad \text { pos-sit }
$$
$t_{i}$ SOVAux

\footnotetext{
${ }^{7}$ In contrast, given the rich agreement found in Latin verbal paradigms, I assume V-to-T movement to take place in clauses with a single 'synthetic' verb form, like (1a) and (2a). As a result, in these contexts there is no overt element that allows us to tell apart the two VP-internal object positions.

${ }^{8}$ Strictly speaking, it is not entirely certain whether the object in (6b) is VP-internal, as we cannot rule out the possibility that (i) the subject DP has undergone string vacuous movement out of the VP and (ii) the object has been scrambled out of the VP.
} 
that slave-NOM favour-ACC give-PR.INF be.able-SUBJ.3SG

'... that a slave can do a favour' (= Sen. Ben. 3.19.1)

The same alternation can be observed in clauses where no VP movement has taken place (AuxVP-clauses). Again, I take the VO-order to be base-generated and the OV-order to be derived $:^{9}$

(7) a quod neque mater pot-est [subfer-re lac], SAuxVO because neither mother.NOM be.able-PR.3SG offer-PR.INF milk.ACC 'as the mother is neither able to offer enough milk, nor ...' (= Var. Agr. 2.4.19)

b Ut ecce peregrin-i pot-era-nt [fideicommiss- $a_{i}$ cap-ere $t_{i}$ ] SAuxOV as PRT foreigners-NOM be.able-IMPF-3PL bequests-ACC receive-PR.INF 'as foreigners could receive testamentary bequests' (= Gai. Inst. 2.285)

With Ledgeway (2012), I will assume that the OV-orders in (6b) and (7b) are derived by means of strictly local roll-up movement, which can informally be defined as a movement operation which displaces $\mathrm{YP}$, the complement of $\mathrm{X}^{\circ}$ to a specifier of $\mathrm{X}^{\circ}$. Here, I will adopt the formalization proposed in BHR (2014). These authors assume that all instances of syntactic movement are triggered by a general feature which they symbolize as ^ ('caret'). More precisely, $\wedge$ is conceived of as a 'diacritic', which can be associated with a number of other syntactic

\footnotetext{
${ }^{9}$ Here too (cf. the previous footnote), an alternative parse is theoretically possible, namely one in which the object has been extraposed and thus does not surface in a VP-internal position.
} 
features. The type of movement ${ }^{\wedge}$ gives rise to depends on the nature of the host feature: for instance, when ^ is associated with a an 'edge feature' on the highest head of a cyclic domain, it gives rise to A'-movement; when it is associated with $\varphi$-features on T, one gets A-movement to Spec,TP. Importantly, BHR also propose that ${ }^{\wedge}$ can be attached to a category-defining feature (see below), in which case it triggers the type of strictly local roll-up movement which we need here.

Consider how this system works when applied to a Latin VP. I will assume that an extended projection starts with an a-categorial root, which I take to denote only some very basic conceptual content. If subcategorized for one, this root can be merged directly with a complement XP (Harley 2014). This yields the very basic structure in (8a), where IA stands for 'internal argument':

a

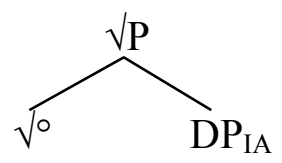

What is added next to the structure is a category-defining head: in the case at hand, this is $v$, which can be considered a (possibly phonologically null) 'verbalizing affix':

b

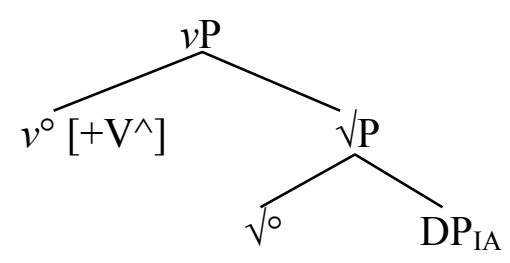

Next, I assume that the root head-moves to $v$ :

c

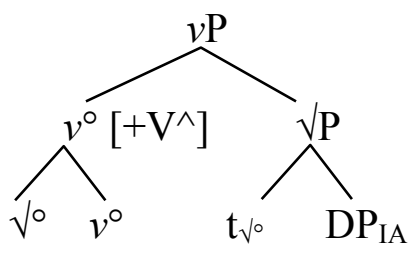


Importantly, the functional head $v$ is endowed with a set of features (between square brackets): one is the category-defining feature ' $\mathrm{V}$ ', which specifies that the relevant node is part of a verbal extended projection, and the other is the movement triggering feature ${ }^{\wedge}$, which in this case gives rise to roll-up movement. This step is represented in $(8 \mathrm{~d}):^{10,11}$

d

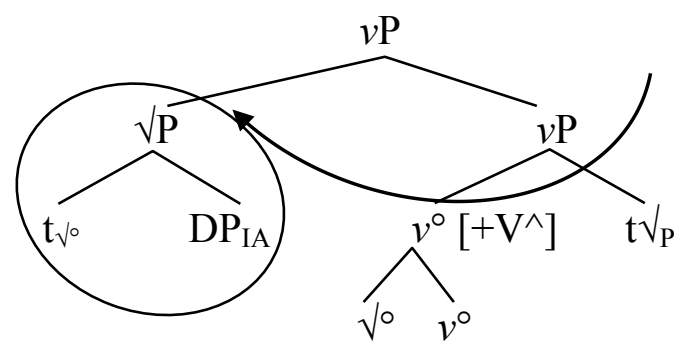

I will consider roll-up movement to be a purely formal type of movement, which only entails that a complement ends up being linearized (pronounced) to the left of its head, and which does not

${ }^{10}$ As indicated in (8d), I will adopt a notational convention in terms of traditional X'-theory, whereby categories displaced by means of roll-up movement appear as sisters to the maximal projection of their (c- or s-)selecting head. In contrast, all other specifiers (externally merged, Aand A'-moved XPs), are represented as sisters to bar level projections. When co-occurring, specifiers created through roll-up dominate inner specifiers.

${ }^{11}$ Observe that this structure, where the head-final $v \mathrm{P}$ dominates the head-initial $\sqrt{ } \mathrm{P}$, would be ruled out under the purely representational conception of FOFC given in (4). Given the acategorial status of (the projection headed by) the root (and the concomitant absence of a host for the roll-up triggering variety of the ${ }^{\wedge}$-feature), no such problem arises under the revised formulation of FOFC to be introduced shortly (cf. (9) below). 
give rise to any special interpretation of the object it displaces (unlike other types of leftward movement, such as scrambling and topicalization). ${ }^{12}$

Finally, to conclude the construction of the thematic domain of the clause, the functional head 'Voice' is added to the structure. This I take to be the locus where the active/passive character of the clause is determined, and where an external argument is/can be introduced ${ }^{13}$. This last step is detailed in (8e), where all terminals are highlighted in boldface, and where EA stands for 'external argument':

$$
\mathrm{e}
$$
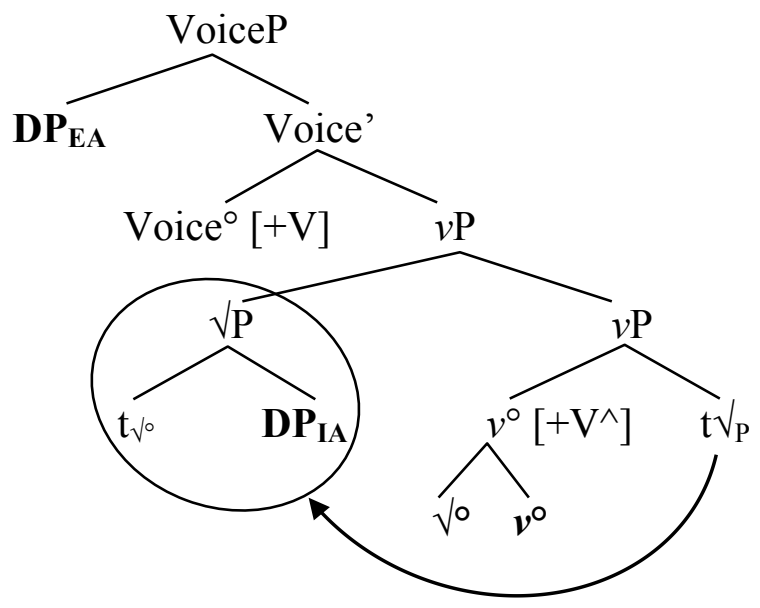

Importantly, observe that the newly merged functional head 'Voice' has a slightly different feature specification than $v$ : although it shares the same categorial feature ' $\mathrm{V}$ ', it is not endowed

${ }^{12}$ In other words, I take it that there are two VP-internal positions for discourse-neutral objects, without excluding that additional low positions for e.g. new information foci were available, as hypothesized in Danckaert (2012: chapter 7).

${ }^{13}$ On VoiceP, see Kratzer (1996). For a three-way decomposition of the verb phrase very similar to the one assumed here, see among others Anagnostopoulou (2003), Harley (2013) and Legate (2014). 
with the movement triggering diacritic '^’ . As a result, no further roll-up movement takes place. At this stage of the derivation, the word order we obtain is ' $\mathrm{SOV}$ '.

Before we proceed, let me just point out that a clause with the order ' $(\mathrm{S}) \mathrm{VO}$ ' can be considered to be only minimally different from the derivation that we have just discussed, in that $v$ does not have the ${ }^{\wedge}$-feature, resulting in total absence of roll-up movement.

\subsection{VPAux: non-local A-movement}

I now turn to the second head-final sequence, viz. VPAux, which was discussed earlier in Danckaert (2014). An obvious hypothesis to explore is whether this too is derived through roll-up movement. The system outlined in BHR (2014) allows for this, but only under certain conditions. More specifically, BHR propose that the movement triggering feature can 'spread' upwards inside an extended projection (EP), associating itself with higher heads, and at each step triggering leftward movement of complement XPs. ${ }^{14}$ Importantly, a configuration in which multiple occurrences of the movement-triggering feature are present inside one and the same EP is argued to be subject to (a representational version of) Relativized Minimality (Rizzi 1990). Concretely, given a span of heads $\mathrm{X}^{\mathrm{i}}, \mathrm{X}^{\mathrm{i}+1}$ and $\mathrm{X}^{\mathrm{i}+2}$, which all share the same categorial feature and are part of the same $\mathrm{EP}$, if $\mathrm{X}^{\mathrm{i}+2}$ has the movement triggering diacritic associated with its categorial feature, then so do both $X^{i}$ and $X^{i+1}$. Thus BHR (2014: 209):

' $[\mathrm{H}]$ ead-final order can be derived by complement movement, as long as, when iterated, complement movement starts at the bottom of the tree and iterates monotonically up the

\footnotetext{
${ }^{14}$ See Grimshaw (2005) (and BHR 2014: 211) for a precise definition of the concept of 'extended projection'.
} 
tree. The iterations can stop at any point (as designated in the grammar of the language), as long as the stopping is "permanent" - that is, as long as complement movement does not “start again" in a higher position within the same extended projection'.

More formally (BHR 2014: 210, their (69)):

(9) If a head $\alpha_{i}$ in the extended projection EP of a lexical head L, EP(L), has ${ }^{\wedge}$ associated with its $[ \pm \mathrm{V}]$-feature, then so does $\alpha_{i+1}$, where $\alpha_{i+1}$ is c-selected by $\alpha_{i}$ in $\operatorname{EP}(\mathrm{L})$.

Let us consider what this means for the derivation of Latin VPAux-clauses like (6b), repeated here for convenience.

$$
\begin{aligned}
& \text { [...] quin seru-us benefici-um da-re pos-si-t } \\
& \text { that slave-NOM favour-ACC give-PR.INF be.able-PR.SUBJ-3SG } \\
& \text { '... that a slave can do a favour.' (= Sen. Ben. 3.19.1) }
\end{aligned}
$$

I will take it that (finite) possum ('be able') is merged in some functional head in the articulated T-domain, and that it forms a single EP together with its infinitival complement (Cinque 2004). In order to derive the word order in (10) by means of roll-up movement, we would have to assume that ${ }^{\wedge}$ is associated with all functional heads up to the T-head where the modal resides. This would (minimally) yield the series $v\left[+\mathrm{V}^{\wedge}\right]$, Voice $\left[+\mathrm{V}^{\wedge}\right]$ and $\mathrm{T}\left[+\mathrm{V}^{\wedge}\right]$, with two more applications of roll-up movement than in (8e). In a first stage, $v \mathrm{P}$ would be moved to an outer specifier of VoiceP on top of the inner specifier hosting the external argument, which results in the linear order 'OVS'. Next, after the merger of the T-projection hosting the modal, VoiceP as a 
whole would move to SpecTP, giving the order 'OVSAux'. If we were to assume that subsequent EPP-driven movement of the subject DP takes place (for instance to a specialized SubjP, cf. Cardinaletti 2004), we would effectively derive the desired order 'SOVAux'.

However, as pointed out in Danckaert (2014), there reasons to assume that this scenario is problematic. Evidence comes from negated VPAux-clauses as in (11), in which non 'not', the marker of sentential negation, intervenes between the lexical verb and the auxiliary:
(11)a quod diut-ius
[labor-em fer-re]
OVNegAux
because long-COMP.ADV effort-ACC endure-PR.INF
non pos-se-nt.
not be.able-IMPF.SUBJ-3PL
'because they could no longer endure the suffering.' (= Caes. B. Gal. 7.20)
b Ill-e
[ut-i ill-o]
non pot-erit?
VONegAux
that-NOM.M.SG use-PR.INF that-ABL.N.SG not be.able-FUT.3SG
'Won't he be able to use it?' (= Sen. Ben. 7.18.2)

\begin{abstract}
Although the order 'VNegAux' is the most frequently attested one (Kühner and Stegmann (1966²: vol. 2.1, 818), non in VPAux-clauses can also appear more to the left, yielding orders like 'SO-Neg-VAux' and 'Neg-SOVAux'. In addition, auxiliaries can also appear more leftward (cf. 'AuxSOV'), but crucially, they can only do so in the absence of non, provided that the latter has sentential scope (Danckaert 2012: 12-6; 2014). In other words, what is never found is word orders like 'AuxSO-Neg-V' or 'AuxNegSOV'. Assuming that both the verb and non are syntactic heads, this restriction can naturally be explained in terms of Travis' (1984) Head Movement
\end{abstract}


Constraint (HMC). Next, observe that the dependent infinitives ferre 'endure' and uti 'use' in (11) do occur to the left of negation, suggesting that their derived position is the result of XP rather than $\mathrm{X}^{\circ}$-movement. ${ }^{15}$ In addition, the negation facts also suggest that this XP-movement cannot be roll-up movement. Recall that, by assumption, roll-up always starts at the bottom of an EP. Assuming a base structure as in (12a), we see that roll-up can never derive the order VP-NegAux, but only the impossible order VP-Aux-Neg (12b) and the possible (but not at issue) order Neg-VP-Aux (12c):

${ }^{15}$ Coordination facts (as in (i), which is most plausibly analysed as involving two coordinated head-initial verb phrases, simply labelled as 'VP' here) confirm that the bracketing of the VOAux-clauses is as in (ii), with the string VO forming a constituent to the exclusion of the auxiliary.

(i) ne qui-s [\&p [vp occul-ere quicquam $] \quad\left[\&^{\circ}\right.$ aut $[\mathrm{vp}$ lest anybody-NOM hide-PR.INF something.ACC or segrega-re caus-am su-am]]] pos-si-t separate-PR.INF cause-ACC his-ACC be.able-PR.SUBJ-3SG 'so that nobody may be able to hide anything or put aside any of his property.' (= Tac. Hist. 4.64)

(ii) $\quad\left[\mathrm{FP}\left[\mathrm{vP} V \mathrm{VP} \mathrm{OBJ}_{\mathrm{O}}\right]_{\mathrm{i}}\left[\mathrm{TP}\left[\mathrm{T}^{\circ}\right.\right.\right.$ Aux $\left.\left.\left.\mathrm{t}_{\mathrm{i}}\right]\right]\right]$

See Danckaert (in progress) for additional discussion of the constituency of VOAux-clauses. 


$\begin{array}{rlr}\text { (12)a } \quad \text { Neg }>\text { Aux }>\text { VP } & \text { base order (no roll-up) } \\ \text { b } \quad \text { VP }>\text { Aux }>\text { Neg } & \text { full roll-up } \\ \text { c Neg }>\text { VP }>\text { Aux } & \text { partial roll-up }\end{array}$

I will take it that the presence of 'V-Neg-Aux' clauses (which also occur with compound tenses involving a BE-auxiliary) in the PLD present the language acquirer with sufficient evidence not to postulate a roll-up derivation. Instead, what seems to be at work is a less local type of movement, which targets a functional projection which is higher than Neg and T. However, it has to be lower than C, as left peripheral XPs in Latin surface to the left (12a) rather than to the right of subordinating conjunctions (Danckaert 2012).

Adopting a parameterized approach to EPP-checking (as initiated by Alexiadou and Anagnostopoulou (1998), and further elaborated in Biberauer (2003) and Biberauer and Roberts (2005)), I will assume that the VP undergoes EPP-driven A-movement to a position in the high middle field, a hypothesis that was also put forward in Danckaert $(2011,2012)$ and Mackenzie and van der Wurff (2012). ${ }^{16}$ I will simply call the target site of this operation 'FP', a functional projection where the clausal EPP-requirement is encoded, and which is distinct from Cardinaletti's (2004) SubjP (which I take to host subject DPs that act as the 'subject of predication'). As indicated in the trees in (13), I assume the relevant head to come with the feature specification $\left[+\mathrm{V},+\mathrm{EPP}^{\wedge}\right]$, which results in A-movement to SpecFP. One can understand this operation as involving pied-piping, where it is actually (the $\varphi$-features of) the highest VPinternal argument DP which is probed for. For reasons of space, I cannot here provide further evidence of this particular analysis. Suffice it to say that there is reason to assume that Classical

${ }^{16}$ On the possibility for VPs to check satisfy the EPP requirement, see also Travis (2005). 
Latin VPAux-clauses (i) are derived by means of VP movement (cf. absence of HMC-effects when non-finite verbs cross negation) and (ii) that this movement operation is not strictly local. The reader is referred to Danckaert (2014; in progress) for additional evidence in favour of the claim that Classical Latin employs VP movement to satisfy the EPP.

A summary of the analysis thus far is provided in the trees in (13), which show a VPAuxclause in which roll-up movement has applied inside the displaced VP (yielding the order SOVNeg-Aux) (13a), and one in which the moved VP is head-initial (13b), which corresponds to the surface order SVO-Neg-Aux. Circled phrases have undergone roll-up movement, boxed phrases have been A-moved. For the sake of simplicity, I assume that the modal sits in $\mathrm{T}^{\circ}$, and that it simply takes an extended verb phrase (VoiceP) as its complement:

(13) a

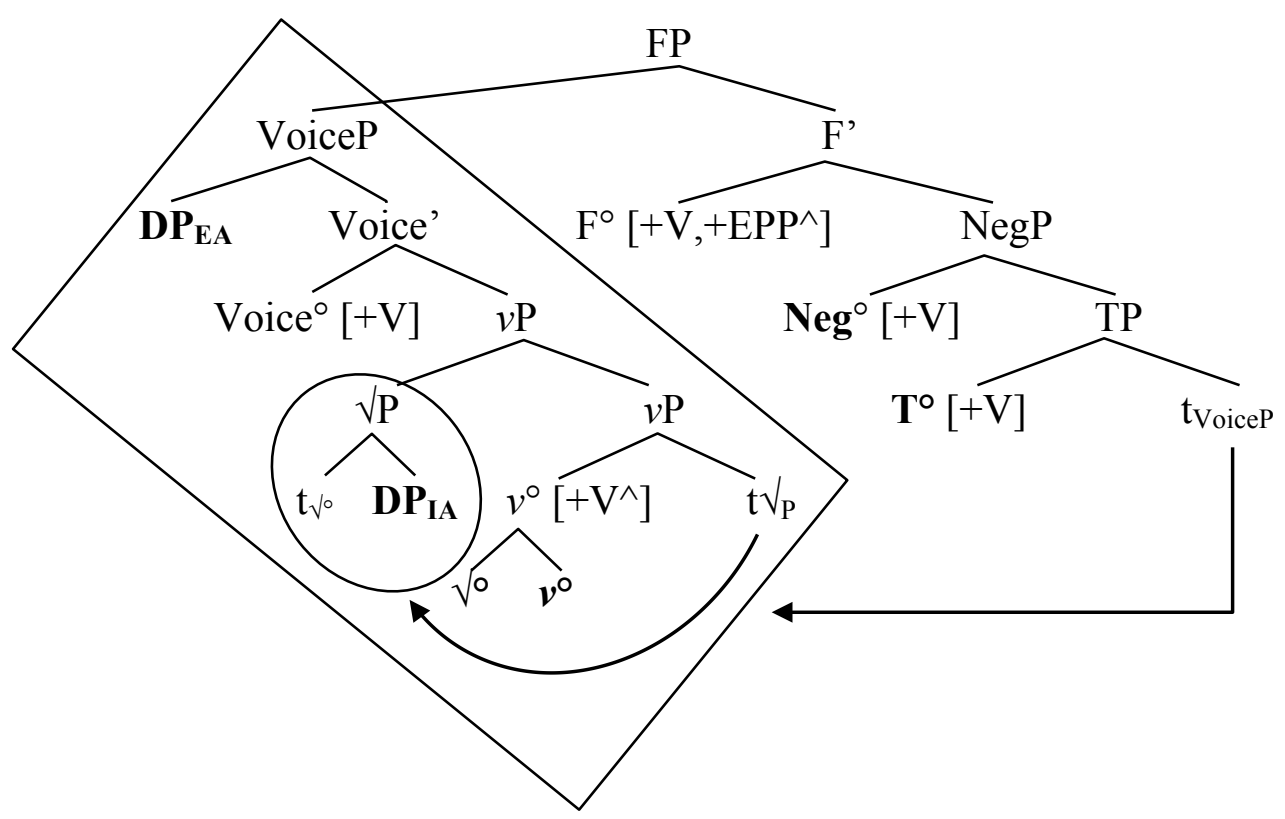

b

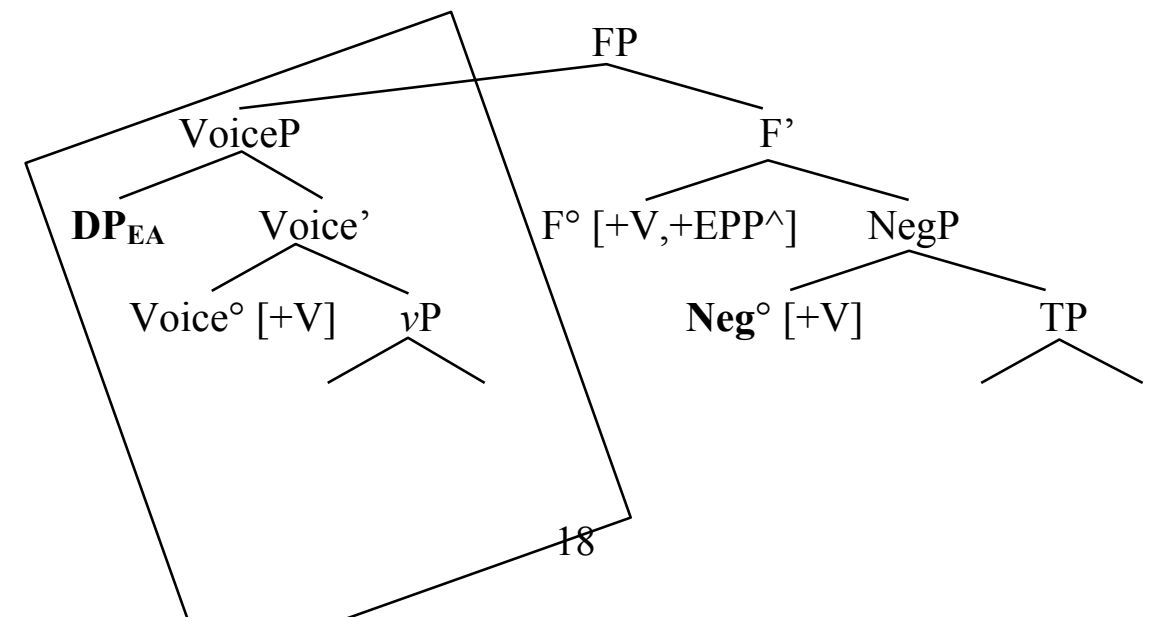



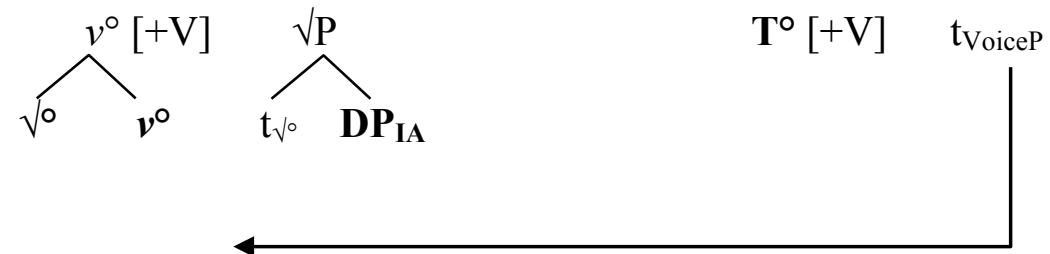

The tree in (13b) now allows us to see why - if the analysis pursued here is on the right track Classical Latin allows for the linear order VOAux: given that VP displacement is triggered by a feature associated with an EPP-feature and not with a categorial feature, the relevant operation is not subject to FOFC.

As we will see in the following section, corpus data show that the VOAux pattern is only very rarely attested in Late Latin, suggesting that the grammar of this language is crucially different from the one of Classical Latin.

3. The diachrony of VOAux

\subsection{A corpus study}

The texts that I have investigated come from a long period of six centuries, which naturally falls apart into two subperiods, separated by a period from which fewer (especially non-Christian) texts are preserved. We can distinguish an earlier period from ca. $60 \mathrm{BC}$ (taken as an average date of composition of Cicero's writings) until ca. $170 \mathrm{AD}$ (Gaius) and a later period from ca. 350 (Palladius) until $590 \mathrm{AD}$ (Gregory of Tours).

A full description of the corpus is given in Table x.1. As indicated in the last column, the consulted text editions were either taken from the annotated database Hyperbase (Brunet and Mellet n.d.) or from the non-annotated online database Brepolis (www.brepolis.net). 
$<$ insert Table x. 1 here $>$

From this corpus, 2910 clauses were collected, all containing (i) a form of the modals possum 'be able' or debeo 'have to' (cf. section 1.3), (ii) a transitive infinitive (V) and (iii) an NP (DP) direct object (O). I included objects with structural (accusative) as well as inherent (genitive, dative or ablative) case. The quantitative results are summarized in Tables x.2 and x.3:

$<$ insert Table x.2 here $>$

$<$ insert Table x.3 here $>$

\subsection{Discussion}

The diachronic evolution of the VOAux pattern is diagrammed in Figure x.1. The data taken into account here are only a subset of the corpus reported on in Tables x.2 and x.3, namely VPAuxclauses with a VP-internal object (i.e. all AuxVP-clauses as well as VAuxO orders (i.e. VPAuxclauses with an extraposed object) were excluded). What is plotted is the relative frequency of head-initial VPs in VPAux-clauses (as compared to the incidence of head-final VPs):

$<$ insert Figure x.1 here $>$

As insertwable the 1 hhere the regression line, we observe an initial rise of head-initial VPs in VPAux-clauses, followed by a fairly abrupt decline of this pattern, apparently starting mid-way 
the second century $\mathrm{AD}$. When we compare the average frequency of the order VOAux in the periods before and after the time gap in the corpus, it appears that the order VOAux is attested in $18.33 \%$ of the VPAux-clauses in the earlier period, as compared to $6.10 \%$ in the later period. This difference is statistically significant (Independent samples T-test, equal variances assumed after logarithmic transformation with added constant $(+1), p=.02774)$.

Before we conclude that this difference is indeed real, we have to rule out the possibility that the observed decline is an accidental by-product of the decline of one of the ingredients of VOAux, viz. the order VPAux. As can be deduced from Tables x.2 and x.3, VPAux is less frequently attested in the later period $(62.15 \%$ in the earlier vs. $33.99 \%$ in the later period; this difference is statistically significant (Independent samples T-test, $\mathrm{p}=.02)$ ). ${ }^{19}$

If we assume that 'VOAux = VPAux + VO', we predict the combined rates of VO and VPAux to provide an accurate estimate of the frequency of VOAux. The predicted and the observed frequencies of VOAux are given in Table x.4. ${ }^{20}$ The third column shows the 'prediction error', i.e. the difference between the observed and the predicted values: the closer this prediction error to zero, the more accurate the estimate.

\footnotetext{
${ }^{19}$ Note that, contrary to what is often claimed, the overall frequency of the order VO (i.e. the second ingredient of the VOAux-pattern) remains almost perfectly constant through time, at 23.09\% in the early period, and $23.11 \%$ in the later (values averaged over VPAux and AuxVPcontexts). As expected, the difference between these two averages cannot be shown to be statistically significant (Independent samples T-test, equal variances assumed, $\mathrm{p}=.998$ ). See Danckaert (in progress) for more detailed discussion.

${ }^{20}$ The predicted rate of VOAux is the product of the frequencies of VO and VPAux given in Table x.3.
} 
$<$ insert Table x.4 here $>$

Two interesting conclusions can be drawn from these figures. First, the prediction error for the 6 last data points (cf. the shaded cells in Table x.4) is consistently positive, implying that the actually observed values are lower than what we expect if the observed decline were only an effect of the reduced frequency of VPAux-clauses, assuming everything else to remain the same. We can conclude that the decline of VOAux is independent of the decline of VPAux. Second, the range of the variation is much wider in the first period (the difference between the lowest and highest error being 35.47 units in the early period, compared to 6.22 in the later). This suggests that word order variation in Classical Latin is not solely governed by syntax. Rather, I take it that the grammar could generate a number of orders, and that the eventual choice between those options was to a large extent governed by usage-based factors. In Late Latin on the other hand, such usage-based factors were to a large extent outranked by syntactic constraints, with a reduction of word order variability (and lower prediction errors) as a result. In what follows, I will propose that one such syntactic constraint is FOFC, which in Late but not in Classical Latin restricts word order in pre-Aux VPs.

\subsection{A hypothesis}

In section 2.2 it was argued that in Classical Latin, negated clauses with an auxiliary and a nonfinite lexical verb (like (11) above), which typically feature the order 'VP-Neg-Aux', provide the language learner with evidence that VPAux-clauses do not involve roll-up movement, as the 
negator non 'not' intervenes between the right boundary of the displaced VP (VoiceP) and the auxiliary. Moreover, the interaction with verb movement suggests that in Classical Latin, the preverbal negator is a syntactic head. The syntax that was proposed for this stage of the language correctly predicts the word order VOAux to be available.

The hypothesis that I will explore is that during the transition from Classical to Late Latin, non ceases to count as a 'boundary' between a moved VP and an auxiliary. I will suggest that non incorporates into the verbal head in $\mathrm{T}$ through a process of procliticization, thus forming a complex head 'Neg-T' ('Neg-Aux'). Once this evolution has taken place, the language learner is no longer confronted with any strong indications that a VPAux-clause does not involve roll-up movement. As I will argue in section 5, this opens up the way for reanalysing an A-moved VP in SpecFP as a structure in which all complement-head sequences are derived through roll-up. First, I will elaborate on the evolution of sentential negation.

4. The diachrony of Latin negation

\subsection{Jespersen's cycle}

The evolution of the Latin preverbal negator non argued for in this section can plausibly be considered part of Jespersen's cycle, i.e. the well-documented tendency for the evolution of negation markers to follow a fixed cyclic pattern (see Jespersen $\left.1966^{2}[1917]\right) .{ }^{21}$ A detailed

\footnotetext{
${ }^{21}$ For recent discussion, see (among many others) van Gelderen (2008, 2011: chapter 8), Jäger (2008) and the contributions in Larrivée and Ingham (2011); particularly on Latin and Romance, Schwegler (1983, 1988) and Fruyt (2011: 707-23).
} 
structure of Jespersen's cycle is given in (14) (from Breitbarth and Haegeman 2009: section 1.2, their (2)):

(14) Stages in Jespersen's cycle:

stage 1 single (preverbal/clitic) negation marker

stage 2 single (preverbal/clitic) negation marker plus optional phrasal emphasizer stage 3 bipartite or embracing negation

stage 4 bipartite or embracing negation with the original marker having become optional and the original emphasizer having become the neutral negator stage 5 single (phrasal) negation marker grammaticalized from the original emphasizer (stage 1' this marker becomes weakened to a clitic (preverbal) marker again)

Latin and its daughter languages provide some nice illustration of (16). (Classical) Latin nōn itself is a contraction of two elements which arguably at some point formed a 'bipartite' negator (stage 3 in (14)), viz. (i) ne, the negator inherited from the Indo-European mother language and (ii) the emphasizer oinom 'one'. ${ }^{22}$ I take it for granted that at the point where these two elements were fused together, the resulting lexical item was a phrase $(\mathrm{XP})$ rather than a head $\left(\mathrm{X}^{\circ}\right)$, and that only later it weakened to become the syntactic head that we can identify in the historical records (cf. van Gelderen’s (2004, 2008, 2011) economy-based ‘Head Preference Principle’).

Furthermore, we also know that the descendants of Latin non in at least some of the present day Romance languages are preverbal clitics (on French, see Kayne 1991; Rowlett 1998; on

${ }^{22}$ cf. Ernout and Meillet (19854: 444); Fruyt (2011: 709-10). 
Italian, see Zanuttini 1997 (modern Italian varieties), 2010 (Old Italian); Manzini and Savoia 2011: chapter 4). For instance, Italian non canonically appears left adjacent to the highest verb, and can only be separated from it by clitic pronouns (arguably also $\mathrm{X}^{\circ}$ 's, attached to the verb at an earlier point in the derivation). The same holds for French $n e$, to the extent that this element is expressed at all.

The following three stages can thus be reconstructed with sufficient confidence. First, Latin noenom/nōn set out as a strong (phonologically independent), phrasal marker of sentential negation (stage 5). Second, nōn gradually weakened to become a syntactic head. As a result, it obtained its strict preverbal position (viz. by virtue of the HMC). Third, (at least some) modern Romance preverbal negators that derive from Latin non are proclitic to the highest verb in their clause.

\subsection{Neg-incorporation, and its consequences}

I would like to propose that Classical and Late Latin constitute two different substages of stage 1 in (14), namely one in which non is already an $\mathrm{X}^{\circ}$ but not yet proclitic, and one in which it becomes even weaker and is incorporated into the highest verb of the clause. ${ }^{23}$ The intuitive rationale behind this is that weakening of the XP non $(<*$ noenom $)$ to clitic non/ne was a gradual process, which did not take place overnight. A number of substages are represented in (15). In (15a), the negative head non and the verb in T are still separate. As we have seen earlier, right on top of NegP, there is FP, whose head is endowed with an EPP-feature which at the next stage of the derivation will give rise to the creation of an inner specifier to host a moved XP.

\footnotetext{
${ }^{23}$ One could conjecture that these two stages reflect an increase in 'structural deficiency' (in the sense of Cardinaletti and Starke 1999) of non.
} 
a

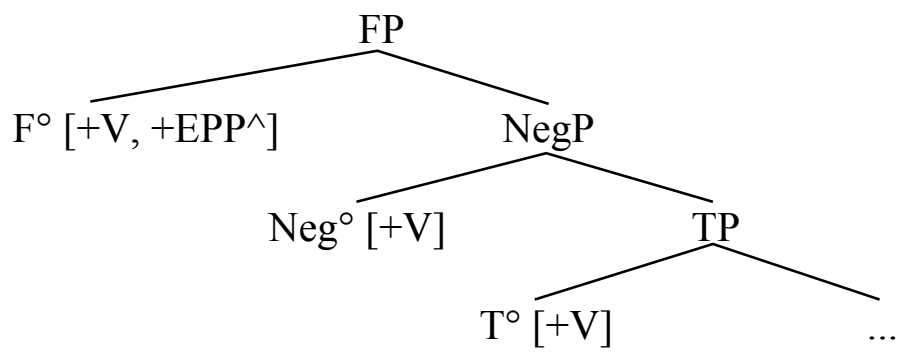

Next, Neg and T form one single complex head in (15b). As indicated, I assume that the syntactic correlate of this process of (pro)cliticization is verb movement to $\mathrm{Neg}^{\circ}$. We can speculate that this step of the process also goes hand in hand with phonological weakening of the negator, but whether this is indeed the case is at this point not obvious to verify.

$\mathrm{b}$

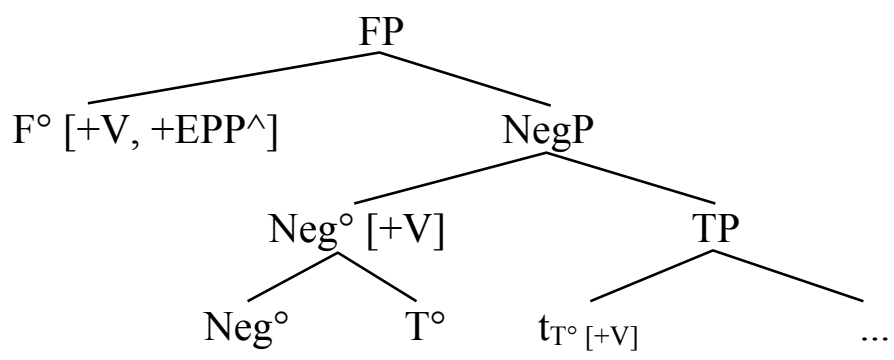

Finally, and very importantly, procliticization of the negator also has consequences elsewhere in the grammar. Earlier, it was argued that the ban on the hierarchically highest verb of the clause to appear to the left of non can be accounted for by calling upon the HMC. In the new grammar, this restriction still holds, but it is an effect of Neg-procliticization rather than of a constraint on movement. On the contrary, there now no longer is any reason why the (complex) verbal head could not move beyond NegP. Imagine that it moves to $\mathrm{F}^{\circ}$, giving rise to the configuration in $(15 c)$ :

c

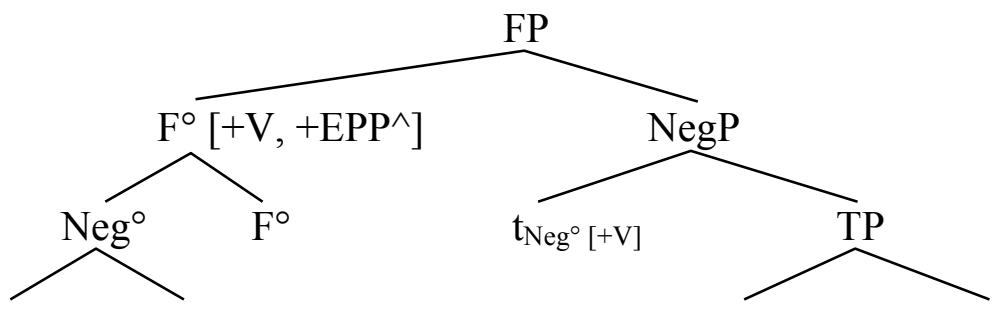




$$
\mathrm{Neg}^{\circ} \quad \mathrm{T}^{\circ} \quad \mathrm{t}_{\mathrm{T}^{\circ}[+\mathrm{V}]} \quad \ldots
$$

In Danckaert (in progress), it is argued at length that this last step is not only available, but that it also becomes the norm: assuming the ${ }^{\wedge}$-feature to be able to trigger both phrasal and head movement, a verbal head endowed with $\varphi$-features is now not only the closest goal for the probing F-head, but it would also be able to move up to $\mathrm{F}^{\circ}$, which effectively makes it possible for the EPP-requirement to be satisfied by means of head movement (an option which is explicitly made available in the systems proposed in Alexiadou and Anagnostopoulou 1998 and Biberauer 2003). Importantly, this development makes EPP-driven movement of VoiceP to SpecFP redundant.

5. Syntactic reanalysis, and the demise of VOAux

We are now in a position to explain the loss of the word order VOAux. Recall from section 3 that the frequency of this pattern drops dramatically in the first half of the second century AD, despite the order VPAux remaining productive (as we have seen, the incidence of the latter decreases too, but at a much slower pace). In other words, there is reason to assume that the order VPAux, despite not being required anymore for the purpose of EPP-checking, was still available in the new grammar (i.e. the grammar with (i) Neg-incorporation and (ii) the new EPP-parameter setting). This state of affairs can naturally be accounted for if we assume that the language learner reanalysed the string 'VP-Aux' as a roll-up structure, in which a large portion of the extended projection of the verb is moved to an outer specifier of F. Using the same notational conventions as above, the basic configuration thus arrived at can be represented in (16), which is minimally different from (15c) in that also the categorial V-feature of $\mathrm{F}$ now has the movement diacritic (as do all lower functional heads in the same extended projection, given FOFC): 
(16)

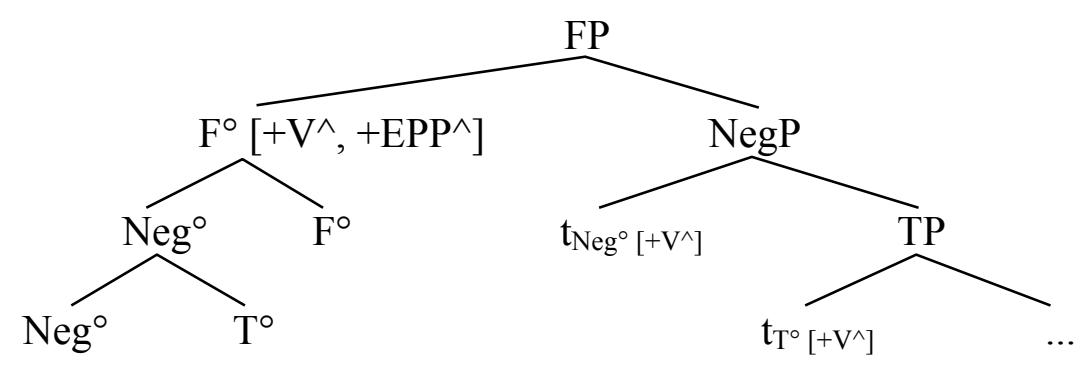

I take it that at the level of FP, $\left[+\mathrm{EPP}^{\wedge}\right]$ triggers head movement, and $\left[+\mathrm{V}^{\wedge}\right]$ roll-up. For instance, a (CS)OVAux-clause like (17) would have the structure in (18):

nisi gemmat-a fibul-a us-us non est

unless jewelled-ABL brooch-ABL used-NOM.M.SG not be.PR.3sG

'unless he did not use a jewelled brooch.'

(= Hist. Aug. Carus, Carinus, Numerianus, 17.1)

$(18)$

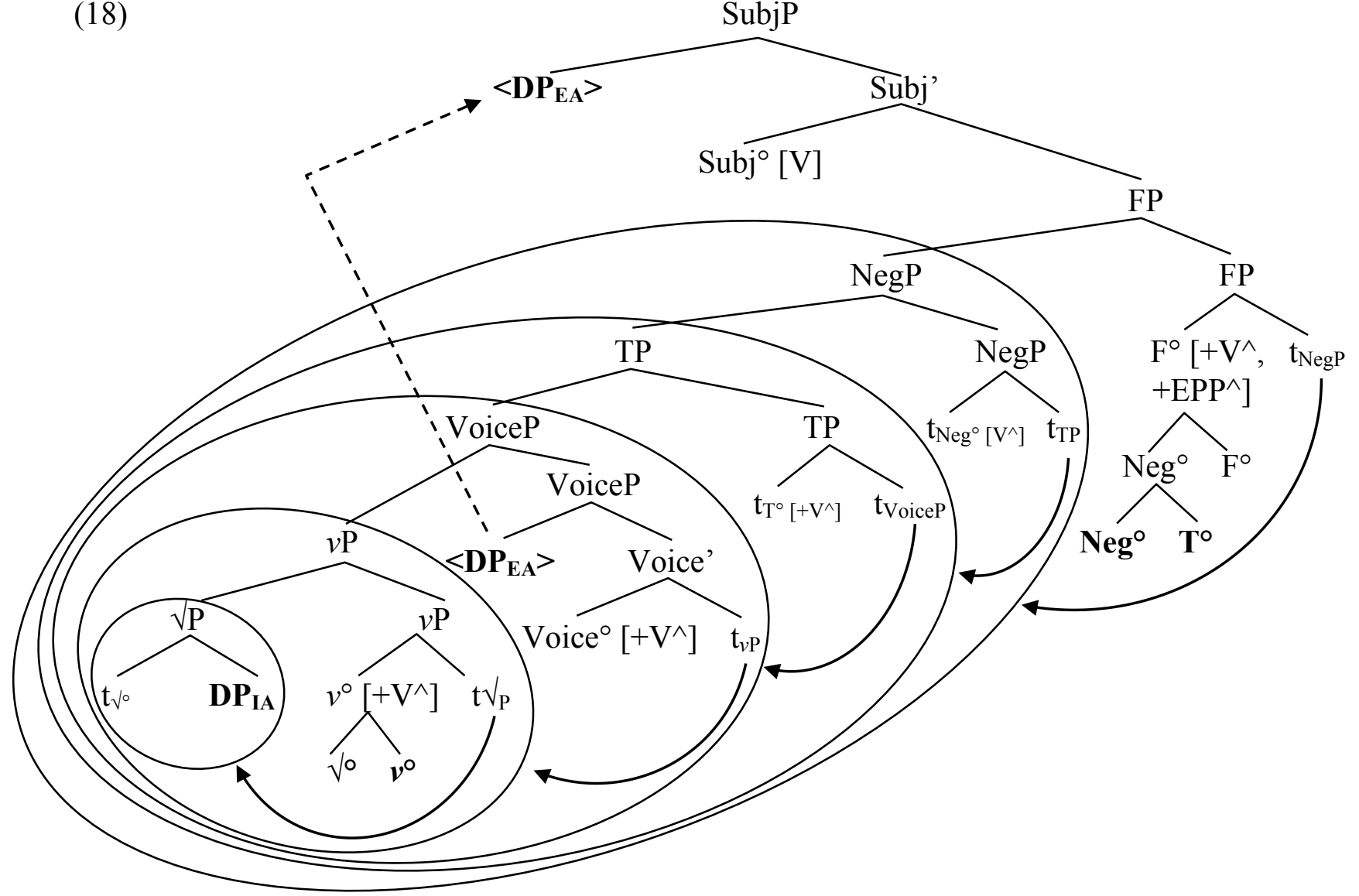


What we see here is a(n admittedly somewhat baroque) 'snowballing' derivation featuring no less than 5 applications of roll-up movement (the effect of some of which is obscured through head movement). In any event, it we adopt FOFC as formulated in (9), the present analysis correctly predicts that whenever the categorial feature of $\mathrm{F}^{\circ}$ is endowed with the movement triggering feature, so is a clausemate $v$, resulting in the (quasi-)systematic co-occurrence of the order VPAux with the order OV (whereas the converse obviously doesn't hold). In other words, Late Latin pre-Aux VoicePs are now subject to FOFC, and the order VOAux is no longer productively available.

\section{Conclusion}

In this paper, I have analysed the diachrony of the Latin word order pattern VOAux. I have proposed that in Classical Latin VPAux-clauses involve a derivation in which the VP undergoes EPP-driven A-movement, an operation which is not subject to the (revised) 'Final-Over-Final Constraint'. I proceeded to suggest that in Late Latin this operation was reanalysed as an instance of roll-up movement, which is subject to FOFC. The crucial factor making this reanalysis possible is incorporation of the proclitic preverbal negator non into the hierarchically highest verb of the clause. As a result, the pattern VOAux is available in the earlier but not in the later period.

\section{References}

Aboh, Enoch (2004). 'Snowballing Movement and Generalized Pied-piping', in A. Breitbarth 
and H. van Riemsdijk (eds), Triggers. Berlin: Mouton de Gruyter, 15-47.

Alexiadou, Artemis and Elena Anagnostopoulou (1998). 'Parametrizing AGR: Word Order,

Movement and EPP-checking', Natural Language and Linguistic Theory 16, 491-539.

Anagnostopoulou, Elena (2003). 'Participles and Voice', in A. Alexiadou, M. Rathert and A. von

Stechow (eds), Perfect Explorations. Berlin: Mouton de Gruyter, 1-36.

Biberauer, Theresa and Ian Roberts (2005). 'Changing EPP Parameters in the History of English:

Accounting for Variation and Change', English Language and Linguistics 9: 5-46.

Biberauer, Theresa (2003). Verb second (V2) in Afrikaans: A Minimalist Investigation of Word

Order Variation. Ph.D. diss., University of Cambridge.

Biberauer, Theresa, Anders Holmberg and Ian Roberts (2014). 'A Syntactic Universal and its

Consequences', Linguistic Inquiry 45: 169-225.

Breitbarth, Anne and Liliane Haegeman (2009). Not Continuity, but Change: Stable Stage II in

Jespersen’s Cycle. Ms. University of Cambridge/Ghent University.

Brunet, Étienne and Sylvie Mellet (n.d.). Hyperbase 5.5: Logiciel hypertexte pour le traitement documentaire et statistique des corpus textuels. Base de littérature latine. Bases, Corpus \& Langage (Université de Nice - Sophia Antipolis) and LASLA (Université de Liège).

Cardinaletti, Anna and Michal Starke (1999). 'The Typology of Structural Deficiency: a Case

Study of the three Grammatical Classes', in H. van Riemsdijk (ed.), Clitics in the

Languages of Europe. Berlin: Mouton de Gruyter, 145-233.

Cardinaletti, Anna (2004). 'Towards a Cartography of Subject Positions' in L. Rizzi (ed.), The

Structure of CP and IP, Oxford: Oxford University Press, 115-65.

Cinque, Guglielmo (2004). “'Restructuring' and Functional Structure’, in A. Belletti (ed.),

Structures and beyond. Oxford: Oxford University Press, 132-91.

Cinque, Guglielmo (2005). 'Deriving Greenberg's Universal 20 and its Exceptions', Linguistic 
Inquiry 36: 315-32.

Danckaert, Lieven (2011). On the Left Periphery of Latin Embedded Clauses. PhD diss., Ghent University.

Danckaert, Lieven (2012). Latin Embedded Clauses: the Left Periphery. Amsterdam: Benjamins. Danckaert, Lieven (2014). 'The Derivation of Classical Latin Aux-final Clauses: Implications for the Internal Structure of the Verb Phrase', in K. Lahousse and S. Marzo (eds), Romance Languages and Linguistic Theory 2012. Amsterdam: Benjamins, 141-59.

Danckaert, Lieven (in progress). The Latin Verb Phrase: Existence, Structure and Diachronic Development. Book manuscript, Under contract with Oxford University Press.

Ernout, Alfred, and Antoine Meillet $\left(1985^{4}\right)$. Dictionnaire étymologique de la langue latine: histoire des mots (retirage de la $4^{e}$ édition augmentée d'additions et de corrections par Jacques André). Paris: Klincksieck.

Fruyt, Michèle (2011). 'Grammaticalisation in Latin', in P. Baldi and P. Cuzzolin (eds), New Perspectives on Historical Latin Syntax: vol. 4: Complex Sentences, Grammaticalization, Typology. Berlin: Mouton de Gruyter, 661-857.

Grimshaw, Jane (2005). 'Extended Projection’, in J. Grimshaw, Words and Structure. Stanford (Cal.): Center for the Study of Language and Information, 1-73.

Harley, Heidi (2013). 'External Arguments and the Mirror Principle: on the Distinctness of Voice and v', Lingua 125: 34-57.

Harley, Heidi (2014). 'On the Identity of Roots', Theoretical Linguistics 40: 225-76.

Holmberg, Anders (2000). 'Deriving OV Order in Finnish', in P. Svenonius (ed.), The Derivation of $O V$ and VO, Amsterdam: Benjamins, 123-52.

Jäger, Agnes (2008). History of German Negation. Amsterdam: Benjamins. 
Jespersen, Otto (1966² [1917]). Negation in English and other Languages. Køpenhavn: A.F. Høst.

Kayne, Richard (1991). 'Romance Clitics, Verb Movement and PRO', Linguistic Inquiry 22: $647-86$.

Kayne, Richard (1994). The Antisymmetry of Syntax. Cambridge (Mass.): MIT Press.

Kratzer, Angelika (1996). 'Severing the External Argument from its Verb', in J. Rooryck and L. Zaring (eds), Phrase Structure and the Lexicon. Dordrecht: Kluwer, 109-37.

Kühner, Raphael, and Karl Stegmann $\left(1966^{2}\right)$. Ausführliche Grammatik der lateinischen Sprache. Hannover: Hahn.

Larrivée, Pierre, and Richard Ingham (eds) (2011). The Evolution of Negation: beyond the Jespersen Cycle. Berlin: Mouton De Gruyter.

Ledgeway, Adam (2012). From Latin to Romance: Morphosyntactic Typology and Change. Oxford: Oxford University Press.

Legate, Julie Anne (2014). Voice and v: Lessons from Acehnese. Cambridge (Mass.): MIT Press. Mackenzie, Ian, and Wim van der Wurff (2012). 'Relic syntax in Middle English and Medieval Spanish: parameter interaction in language change', Language 88: 846-76.

Manzini, Rita, and Leonardo Savoia (2011). Grammatical Categories: Variation in Romance Languages. Cambridge: Cambridge University Press.

Rizzi, Luigi (1990). Relativized Minimality. Cambridge (Mass.): MIT Press.

Roberts, Ian (1985). 'Agreement Parameters and the Development of English Modal Auxiliaries', Natural Language and Linguistic Theory 3: 21-58.

Rowlett, Paul (1998). Sentential Negation in French. Oxford: Oxford University Press. Schwegler, Armin (1983). 'Predicate Negation and Word-Order Change: a Problem of Multiple Causation', Lingua 61: 297-334. 
Schwegler, Armin (1988). 'Word-Order Changes in Predicate Negation Strategies in Romance Languages', Diachronica 5: 21-58.

Taylor, Ann and Susan Pintzuk (2011). 'The Interaction of Syntactic Change and Information Status Effects in the Change from OV to VO in English', Catalan Journal of Linguistics 10: 71-94.

Travis, Lisa (1984). Parameters and Effects of Word Order Variation. PhD. diss. MIT. van Gelderen, Elly (2004). Grammaticalization as Economy. Amsterdam: Benjamins. van Gelderen, Elly (2008). 'Negative Cycles', Linguistic Typology 12: 195-243. van Gelderen, Elly (2011). The Linguistic Cycle: Language Change and the Language Faculty. Oxford: Oxford University Press.

Zanuttini, Raffaella (1997). Negation and Clausal Structure: a Comparative Study of Romance Languages. Oxford: Oxford University Press.

Zanuttini, Raffaella (2010). 'La negazione', in G. Salvi and L. Renzi (eds), Grammatica dell'italiano antico. Bologna: Il Mulino, vol. 1, 569-82. 